\title{
O GRUPO FOCAL COMO TÉCNICA DE COLETA DE DADOS NA PESQUISA QUALITATIVA: RELATO DE EXPERIÊNCIA*
}

\author{
Verônica de Azevedo Mazzaㅜ; Norma Suely Falcão de Oliveira Melo²; Anna Maria Chiesa ${ }^{3}$
}

\begin{abstract}
RESUMO: Relato de experiência, com objetivo descrever a utilização do grupo focal com famílias, como técnica de obtenção de dados em pesquisa qualitativa. A organização e planejamento do grupo focal têm impacto direto nos dados coletados, portanto se apresenta esquematicamente as etapas utilizadas neste processo para o planejamento do grupo focal, pois contribuem para obtenção de resultados efetivos na aplicação da técnica. Desta forma, o pesquisador precisa preparar cuidadosamente cada etapa do desenvolvimento do trabalho em grupo. Alguns pontos são relevantes para a coleta de dados, dentre esses a preparação da equipe e ambiente para atender as necessidades das crianças, permitindo assim, que os participantes tenham sua atenção totalmente direcionada para a discussão do grupo. Tendo em vista as peculiaridades da técnica e sua relevância na qualidade dos dados o pesquisador deve se apropriar do seu tema de estudo e planejar o grupo focal delineando-o a partir deste.
\end{abstract}

PALAVRAS-CHAVE: Grupo focal; Pesquisa; Metodologia.

\section{FOCAL GROUPAS ADATAGATHERINGTECNIQUE IN QUALITATIVE RESEARCH: EXPERIENCE REPORT}

ABSTRACT: The paper is an experience report, which aim is to describe the focal group with families as a technique to gather data in qualitative researches. The focal group organization and planning has a direct impact in the data gathered, so the phases used in this process of planning are presented, because it contributes to effective results in the technique development. So, researches should prepare carefully each phase of the group work development. Some points are relevant to data gathering, among these the group preparation and environment to meet the needs of the children, enabling then, that participant may have their focus totally directed to the group discussion. Considering the technique particularities and its relevance to data quality, the researcher should take up with the study theme, and the focal group should be planned accordingly with it.

KEYWORDS: Focal group; Research; Methodology.

\section{EL GRUPO FOCAL COMO TÉCNICA DE COLECTA DE DATOS EN LA INVESTIGACIÓN CUALITATIVA: RELATO DE EXPERIENCIA}

RESUMEN: Relato de experiencia, con el objetivo de describir la utilización del grupo focal con familias, como técnica de obtención de datos en investigación cualitativa. La organización y planificación del grupo focal tiene impacto directo en los datos recogidos, por lo tanto se presentan esquemáticamente las etapas utilizadas en este proceso para la planificación del grupo focal, pues contribuyen para la obtención de resultados efectivos en la aplicación de la técnica. De esta forma, el investigador necesita preparar cuidadosamente cada etapa del desarrollo del trabajo en grupo. Algunos puntos son relevantes para la colecta de datos, entre esos la preparación del equipo y ambiente para atender las necesidades de los niños, permitiendo así, que los participantes tengan su atención totalmente direccionada para la discusión del grupo. Teniendo en cuenta las peculiaridades de la técnica y su importancia en la calidad de los datos, el investigador debe apropiarse de su tema de estudio y planificar el grupo focal delineándolo a partir del mismo.

PALABRAS CLAVE: Grupo focal; Investigación; Metodología.

\footnotetext{
*Artigo a partir da tese "Necessidades das famílias com relação ao desenvolvimento infantil à luz da promoção da saúde”. Programa de Pós-graduação da Escola de Enfermagem da USP. Ano de defesa, 2007.
}

\footnotetext{
${ }^{1}$ Enfermeira. Doutora. Professora do Departamento de Enfermagem. Bolsista CNPq. Membro do Grupo de Estudos Família Saúde e Desenvolvimento-GEFASED da Universidade Federal do Paraná-UFPR.

${ }^{2}$ Doutoranda do Programa de Saúde da Criança e do Adolescente. Departamento de pediatria-UFPR. Professora do Curso de odontologiaUFPR.

${ }^{3}$ Enfermeira. Doutora. Professora do Departamento de Saúde Coletiva da Escola de Enfermagem da Universidade de São Paulo-USP. Coordenadora do Grupo de Pesquisa Modelos Tecno-assistenciais e Promoção da Saúde.
}

Autor correspondente:

Verônica de Azevedo Mazza

R. Pe. Camargo, 120 - 80060-240 - Curitiba-PR

Recebido: 10/12/08

E-mail:mazzas@terra.com.br

Aprovado: 25/03/09 


\section{INTRODUÇÃO}

Nos últimos anos a técnica de grupo focal nas pesquisas tem sido amplamente utilizada nos países em desenvolvimento por se constituir uma forma prática, fácil e rápida de se ter contato com a população que se quer investigar ${ }^{(1)}$. Geralmente tem abordagem qualitativa ou se refere a uma complementação de um estudo qualitativo. Também pode subsidiar delimitação de pesquisa, quando ainda não se dispõe de informação suficiente acerca do tema que se pretende investigar; sendo neste caso substancial na formulação do problema ${ }^{(2-3)}$.

Define-se grupo focal como um

conjunto de pessoas, ligadas entre si por constante de tempo e espaço, articuladas por sua mútua representação interna, se propõe explícita ou implicitamente uma tarefa, que constitui sua finalidade $[. . .]^{(4: 395)}$.

Em sua essência esta técnica visa a interação entre os participantes e o pesquisador, a partir da discussão focada em tópicos específicos e diretivos. Tem caráter interpretativo em vez de descritivo. Proporciona respostas consistente, uma vez que estas são elaboradas por muitas pessoas; permitindo que surjam novas idéias ou mesmo idéias originais ${ }^{(1,4-5)}$.

Para além da coleta de dados o grupo focal se constitui foro que facilita expressão das características.

\section{PLANEJAMENTO PARA UTILIZAÇÃO DA} TÉCNICA DE GRUPO FOCAL

A figura 1 apresenta, o esquema do planejamento do uso da técnica de grupo focal neste estudo.

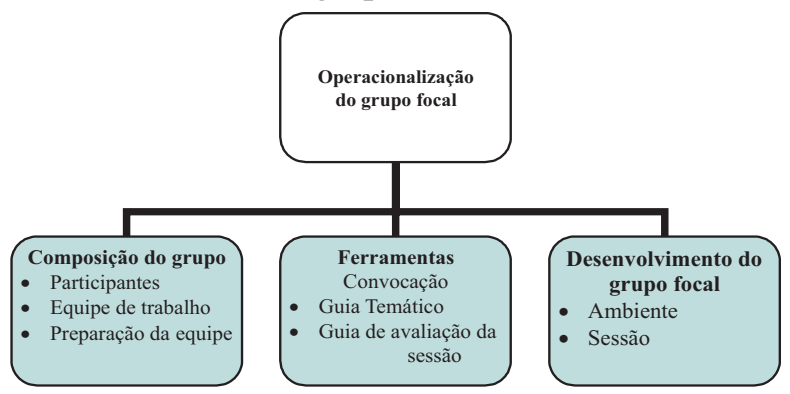

Figura 1- Operacionalização do Grupo Focal Fonte: da pesquisa.

\section{Operacionalização do grupo focal}

É descrito na seqüência como ocorreu a utilização da técnica de grupo focal e, ressalta-se que a operacionalização desta técnica requer algumas condições. O número de participantes deve ser de seis a 15 integrantes, porém para a determinação da quantidade de participantes se deve considerar os objetivos do estudo. O tempo de duração do encontro não deve ultrapassar de uma hora e meia a duas horas, para evitar prejuízo em função do cansaço e desgaste mental, pois este tempo possibilita a discussão das idéias sem levar à exaustão. O trabalho no grupo requer um coordenador e no mínimo um observador ${ }^{(7)}$.

\section{Composição do grupo focal: sujeitos}

Para formação dos grupos focais deste trabalho os critérios foram famílias que tinham crianças até cinco anos de idade, permitindo a semelhança em relação ao ciclo temporal, ou seja, a idade dos filhos proporcionou a similaridade de história de vida das famílias participantes. Estas famílias pertenciam à área de abrangência da unidade de saúde, porém sem necessidade de serem usuários do serviço de saúde.

Em relação ao nível de experiência a formação do grupo contou com a participação de representantes das famílias, que na prática eram os cuidadores. Está condição permitiu a aproximação de experiência e de conhecimento entre os participantes em relação ao cuidado das crianças. A composição dos grupos foi de, principalmente, mães, pai e avó. Está composição permite o reconhecimento da forma como as famílias estão organizadas atualmente para atenderem as necessidades das crianças. Os critérios de faixa etária, estado civil, diferenças culturais e religiosos e de sexo, não foram relevantes de acordo com o objeto da pesquisa, na composição dos grupos.

A equipe de trabalho desta pesquisa foi composta por três pessoas: um coordenador, um observador e um apoio técnico. Uma das funções relevantes desta equipe é de tornar explícitos conteúdos implícitos do grupo, é esclarecer a relação entre significante e significado ${ }^{(7)}$.

O papel do coordenador é fundamental, pois deve facilitar a interação dos participantes e propiciar o pensar e a troca de experiências no grupo. Para tanto, se deve ter claro o objetivo do encontro e o que espera dos participantes. Neste caso, o coordenador era o autor da pesquisa, e tinha experiência com trabalho de grupo. Ainda, o coordenador deve favorecer a integração e a exposição de opiniões; ter postura de facilitador das discussões, intervir verbalmente quando o grupo se encontra numa situação de conflito na qual não pode seguir sozinho ${ }^{(7)}$. Deve ainda, possuir as características: tranquilidade, capacidade de promover a interação, sem 
um comportamento ameaçador; habilidade de ouvir e demonstrar entusiasmo; consciência da comunicação não verbal; capacidade de seleção e instrumentalização dos componentes do grupo e competência para lidar com o inusitado, com o imprevisível ${ }^{(4,7)}$.

O observador registra os acontecimentos no decorrer dos encontros considerando os aspectos verbais e não verbais e, para isto, deve ter capacidade de observação, síntese e conhecimento dos objetivos e objeto da pesquisa. Estas características permitem que o observador atue conjuntamente com o coordenador de forma harmônica ${ }^{(7)}$. Tanto o coordenador como o observador devem ser aptos e experientes, demonstrar segurança e transparência na comunicação para conduzir o grupo e ter objetivos bem definidos e claros.

Para desenvolver a técnica de grupo focal com famílias com filhos pequenos foi imprescindível organizar um espaço para recreação das crianças, pois isto permitiu aos pais ou responsáveis a tranqüilidade para dedicarse as discussões. Este fato é corroborado por CotéArsenault e Morrison-Beedy ${ }^{(6)}$ que em experiência de grupo focal com mães e crianças pequenas relatam que o choro das crianças desvia a atenção das mães do centro da discussão e esta situação pode impossibilitar o retorno da conversa ao mesmo patamar inicial. Para resolver tal situação sugere-se um espaço específico, brinquedos e a presença de um cuidador para atender as crianças, isto possibilita a redução do ruído e mantém a atenção das mães durante as sessões.

Neste trabalho um componente da equipe atuou como apoio técnico com a incumbência de cuidar das crianças que acompanhavam os participantes. Neste sentido, ratificamos como preponderante a presença de um cuidador com uso de recursos lúdicos e local apropriado, para trabalhos com grupo focal que envolvam participantes com crianças ${ }^{(6)}$.

A preparação da equipe é essencial para a qualidade do trabalho, assim a qualificação do coordenador para realização da técnica ocorreu durante o desenvolvimento da tese de doutorado. Demais membros da equipe foram capacitados a partir de leituras, simulações de casos envolvendo erros mais frequentes e graves nos grupos focais e discussões para dirimir dúvidas. Esta etapa serviu para aprofundar e uniformizar o conhecimento da equipe.

Considerando a importância da interação da equipe para este trabalho, foram realizadas algumas reuniões de preparação da técnica, com discussão do guia temático, o objeto e os objetivos da pesquisa e a forma de condução da sessão. Foi estabelecida uma sintonia na comunicação, definindo inclusive, alguns códigos não verbais para serem utilizados durante as reuniões. O observador mantinha a atenção constante durante o trabalho de grupo e com habilidade fazia tanto a análise quanto a síntese das discussões do grupo e quando necessário fazia intervenções verbais para esclarecimento de algumas falas e mesmo para ajudar o coordenador na manutenção dos temas.

Caso algum dos participantes do grupo de pesquisa demonstre inabilidade para este tipo de trabalho, este não deverá participar do grupo focal ou ter sua participação dirigida pelo coordenador. Ao mesmo tempo em que cada componente é considerado individualmente, existe também uma interdependência e um compartilhar de tensão que deve ser cuidadosamente balanceada para otimizar o resultado do grupo focal ${ }^{(4,6)}$.

\section{Ferramentas: convocação do grupo focal}

O sucesso para garantir a presença dos participantes no grupo focal está diretamente relacionado aos recursos de convocação. Este processo ocorreu em três fases: a primeira foi através de visita domiciliar; a segunda por intermédio de convite por escrito e a terceira por meio de telefonema.

A visita domiciliar foi realizada pelo pesquisador e um agente comunitário. A participação desse ator social facilitou o acesso do pesquisador às famílias. Durante a visita domiciliar, além da entrega do convite escrito, realizou-se entrevista para caracterizar a família. Este é um momento de aproximação entre o pesquisador e o participante que pode favorecer a sua presença no grupo focal, bem como é possível perceber os sinais de falta de interesse em fazer parte deste trabalho.

O convite escrito foi realizado na mesma semana da sessão, este continha endereço, data e horário cuja finalidade era fornecer dados ao participante para que lembrasse da data do compromisso. No dia do grupo focal, o convite foi reforçado pelo coordenador mediante contato por telefone. É possível que esta forma de contato com os participantes tenha despertado o sentimento de valorização, haja vista que houve um aumento da participação dos sujeitos nos grupos com os quais utilizamos o contato por telefone, ainda que tivemos nesta interação, alguns relatos de esquecimento. Assim entendemos que os recursos de convocação são relevantes para garantir uma melhor participação.

O guia temático é uma ferramenta norteadora para o desenvolvimento do tema, que auxilia a 
manutenção do propósito do estudo como força condutora do trabalho e apresenta questões que tratam do objeto da pesquisa. Para captação das necessidades percebidas pelas famílias para promoção do desenvolvimento infantil, foi elaborado um guia de tema com 12 questões abertas. Essas questões descritas no Quadro 1, contemplavam os seguintes aspectos: percepção das famílias sobre o processo saúde doença das crianças, necessidades das famílias para o desenvolvimento infantil, os recursos sociais e familiares existentes e necessários para o desenvolvimento infantil.

Quadro 1- Guia de tema do grupo focal. Curitiba, Paraná, 2007

1. Que crianças vocês conhecem e que consideram saudáveis? Por quê?

2. Para vocês quais os principais problemas de saúde das crianças?

3. Como você e sua família percebem que a criança está se desenvolvendo bem? Por quê?

4. O que vocês consideram necessário para a criança crescer saudável?

5. Quais as facilidades que sua familia tem para ajudar no crescimento e desenvolvimento da criança?

6. Quais as dificuldades que a família enfrenta para ajudar no crescimento e desenvolvimento das crianças?

7. Quais são as formas de apoio que a sua família utiliza para ajudar no crescimento e desenvolvimento das crianças?

8. Para vocês que é que mudou na sua família depois do nascimento dos filhos?

9. Que tipo de apoio você encontra no bairro para ajudar sua família no cuidado dos seus filhos?

10. O que vocês acham que falta no seu bairro para ajudar a sua familia no cuidado dos seus filhos?

11. Do que é que vocês sentem falta no bairro e que poderia ajudar no cuidado dos seus filhos?

12. Existe alguma coisa que não foi exposta e sobre a qual você gostaria de conversar ou algo a sugerir?

Fonte: Mazza $^{(8)}$.

O guia de avaliação, Quadro 2, era usado ao final de cada sessão para auxiliar a equipe a identificar as dificuldades e, assim, reorganizar o trabalho para aprimorar as reuniões dos grupos seguintes. Um dos itens observados foi a necessidade de ampliar a

Quadro 2 - Guia de Avaliação do grupo focal.Curitiba/Paraná, 2008 participação de pessoas mais tímidas; outra situação foi a necessidade de melhorar o equacionamento do tempo utilizado para cada tópico de discussão e contribuiu também na uniformização da equipe para uso da técnica de grupo focal.
A organização dos lugares foi boa?

$\mathrm{O}$ ambiente estava tranquilo sem interrupções?

O tempo foi adequado?

O guia temático foi completo, cumpriu sua função?

$\mathrm{O}$ coordenador mostrou-se tranqüilo?

Estimulou a integração do grupo?

Promoveu o entusiasmo e a participação?

Tem atitude imparcial?

Coordena os participantes?

Improvisa quando necessário?

Mantém a conversa centrada no tema?

Evita conversa ao mesmo tempo?

Permite diferenças individuais?

Conserva a espontaneidade do grupo?

Faz participar do debate as pessoas mais tímidas?

Tranqüiliza os participantes?

Adaptado de Debus e Novelli ${ }^{(1: 75)}$.
Explica os objetivos do grupo?

Age com naturalidade?

Apresenta as regras ao grupo?

Proporciona uma boa transição de uma etapa para outra?

Estabelece um bom relacionamento com o grupo?

Reduz o medo de falar dos participantes?

Permite que os membros se conheçam entre si?

Respeita a programação?

Proporciona uma boa transição de uma etapa para outra?

Obtém profundidade nas respostas?

As informações são coerentes?

Sabe repassar bem as informações?

Identifica os temas principais?

Resume as idéias principais?

Identifica as opiniões diferentes? 
Desenvolvimento do grupo focal: organização do ambiente

A escolha do local de realização das sessões do grupo focal tem fundamental importância na adesão dos participantes, portanto é preciso estabelecer um ambiente propício às interações. Este ambiente deve isolar ou diminuir as interferências ambientais como: toques de telefone, chamadas de pessoas e interrupções. Uma das características desta escolha pauta-se nos sujeitos da pesquisa, pois o local deve ser o mais neutro possível, evitando-se espaços que possam trazer conflitos ideológicos, religiosos e culturais. Ainda, o espaço físico deve ser de fácil acesso, e preferencialmente, de conhecimento dos participantes. A sala, dentro do possível, deve ter banheiro próximo e um clima agradável, evitando-se extremos de temperatura, propiciando conforto.

A distribuição dos participantes na sala foi no formato de círculo para favorecer a interação entre eles. Esta distribuição deve promover um bom contato visual entre os participantes e a interação face-a-face; evitando-se assentos com idéia de prestígio ${ }^{(2)}$. Para tanto é preciso cadeiras em número suficiente para todos, e não devem ser fixas para permitir um rearranjo de forma a favorecer a comunicação em grupo e a captação das falas pelos recursos tecnológicos. Assim, o ambiente precisa permitir que os participantes se sintam confortáveis e seguros para exporem suas reais percepções.

Nesta experiência foi utilizada uma sala com aproximadamente $10 \mathrm{~m}^{2}$, cozinha e banheiro. O preparo da sala tinha início com a arrumação dos diferentes ambientes. As cadeiras dispostas em círculo para evitar hierarquia, com definição prévia do local onde estariam sentados observador e coordenador, para possibilitar a comunicação não verbal. O espaço das crianças era constituído de uma mesa ampla com cadeiras e materiais lúdicos. $\mathrm{O}$ ambiente de socialização foi organizado com lanche e bebidas quentes e água para degustação após a sessão.

A acústica da sala e a adequação dos equipamentos de áudio e vídeo são fatores preponderantes para a qualidade das gravações. Recomenda-se que o local seja equipado com aparelhagem para gravação em áudio e/ou vídeo, espelhos para permitir uma visão em uma só direção e salas de observação. Porém, em países em desenvolvimento, raras vezes existem tais instalações, e assim, se recomenda algumas adequações. Prever recursos financeiros para aquisição de equipamentos em número suficiente, bem como, pilhas, fitas K7, remuneração de profissionais para a transcrição das fitas ou programas para transcrição das gravações, pois são aspectos chaves para a elaboração do relatório final da pesquisa ${ }^{(1,2,5)}$.

Nesta experiência relatada, para cada grupo focal, foram utilizados dois gravadores por sessão. Um com duas fitas cassete virgem, com duração de 60 minutos e pilhas novas para evitar interrupções na gravação. O outro, um gravador digital com capacidade de gravação de seis horas. Os gravadores foram distribuídos na sala em contra posição. Para identificação do posicionamento dos gravadores eles foram definidos como "A" e "B". O gravador "A" captava as falas dos participantes que estavam à frente do observador e o gravador "B" dos participantes que estavam à frente do moderador. Esta localização foi dimensionada considerando-se a disposição dos participantes no grupo, para com isto, garantir a gravação das falas de todos os participantes. Ainda, de fundamental importância é o domínio no uso dos equipamentos.

Pelas características dos sujeitos foi feita a opção somente pelo gravador por acreditar que recursos de filmagem ou a presença de espelhos pudessem interferir na espontaneidade dos participantes, ou mesmo expor à constrangimentos. Entretanto, Côté-Arsenault e Morrison-Beedy ${ }^{(6)}$ ressaltam o fato do gravador não ser capaz de registrar os dados não verbais como: a interação do grupo e a expressão de linguagem corporal.

A sessão foi organizada com as seguintes atividades: preparação, apresentação, desenvolvimento, encerramento do grupo e socialização com degustação. Todas as atividades tinham definição de tempo. A preparação com um tempo de 10 minutos, composta pela apresentação dos participantes, breve introdução do tema, apresentação dos objetivos do trabalho, explicação sobre o uso do gravador, da técnica de grupo focal e das questões éticas.

O desenvolvimento foi orientado pelas questões do guia temático com aproximadamente uma hora e 20 minutos, distribuído de acordo com a complexidade de cada tópico a ser discutido. As perguntas iniciais devem ser mais genéricas e depois se direcionando para o principal propósito.

No encerramento o coordenador realizou síntese do trabalho do grupo e fez esclarecimentos a respeito de questões abordadas pelo grupo na perspectiva ética, posicionamento da equipe em relação 
a alguns assuntos e esclarecimento sobre informações contraditórias. Na fase final ocorreu o momento de socialização com degustação de lanche.

\section{CONSIDERAÇÕES FINAIS}

Este trabalho permitiu perceber que para possibilitar a captação efetiva do objeto da pesquisa o uso da técnica de grupo focal deve ser criteriosamente planejada. A organização e planejamento do grupo focal tem impacto direto no resultado dos dados coletados. Portanto, o pesquisador precisa preparar cada etapa do desenvolvimento do trabalho em grupo.

Nesta pesquisa que envolveu famílias com crianças menores as quais tiveram que acompanhar os participantes, alguns pontos foram relevantes para o sucesso do trabalho de coleta de dados. Foi necessária, dentre esses, a preparação da equipe e ambiente para atender as necessidades das crianças, permitindo assim, que os participantes tivessem a atenção totalmente direcionada para a discussão do grupo. Outro fator considerado relevante foi à forma de convocação do grupo para as sessões com a utilização de diferentes recursos para promover a participação dos sujeitos no trabalho de grupo.

Tendo em vista as peculiaridades do grupo focal e influência da sua organização na qualidade do resultado, torna-se imprescindível para o pesquisador apropriar-se do seu tema de estudo para subsidiar o planejamento deste, de acordo com objeto, objetivos e características dos sujeitos da pesquisa propiciando o uso adequado da técnica e consequentemente a obtenção dos dados com maior fidedignidade.

\section{REFERÊNCIAS}

1. Debus M, Novelli P. Manual para excelencia en la investigación mediante grupos focales. Comunication for child survival: Healthcom; 1997.

2. Dall'agnol CM, Trench MH. Grupos focais como estratégia metodológica em pesquisa na enfermagem. Rev Gaúcha Enferm. 1999 Jan; 20(1):5-25.

3. Aschidamini IM, Saupe R. Grupo focal - estratégia metodológica qualitativa: um ensaio teórico. Cogitare Enferm. 2004 Jan/Abr;9(1):9-14.

4. Meier MJ, Kudlowies S. Grupo focal: uma experiência singular. Texto Contexto Enferm. $2003 \mathrm{Jul} / \mathrm{Set} ; 12(3): 394-9$.

5. Lervolino AS, Pelicioni MCF. Autilização do grupo focal como metodologia qualitativa na promoção da saúde. Rev Esc Enferm USP. 2001 Jun;35(2):115-21.

6. Côté-Arsenault D, Morrison-Beedy D. Focus on research methods maintaining your focus in focus groups: avoiding common mistakes. Research in Nursing and Health. 2005;28:172-79.

7. Chiesa AM, Ciampone MHT. Princípios gerais para abordagem de variáveis qualitativas e o emprego da metodologia de grupos focais. In: Chianca TCM, Antunes MJM, organizadores. Classificação Internacional das Práticas de Enfermagem em Saúde Coletiva-CIPESC. Brasília: ABEn; 1999. p.306-24.

8. Mazza VA. Necessidades das famílias com relação ao desenvolvimento infantil à luz da promoção da saúde [tese]. São Paulo (SP): Escola de Enfermagem da USP; 2007. 